\title{
REFLEXÕES TEÓRICAS ACERCA DA CARACTERIZAÇÃO DA RESPONSABILIDADE INTERNACIONAL DE EMPRESAS TRANSNACIONAIS POR VIOLAÇÕES DE DIREITOS HUMANOS
}

\author{
THEORETICAL REFLECTIONS ON THE CHARACTERIZATION OF THE \\ INTERNATIONAL RESPONSIBILITY OF TRANSNATIONAL CORPORATIONS FOR \\ VIOLATIONS OF HUMAN RIGHTS
}

\section{RESUMO}

\author{
${ }^{1}$ Mariana Lucena Sousa Santos \\ ${ }^{2}$ Cristina Figueiredo Terezo Ribeiro
}

Este trabalho pretende analisar as três principais teorias acerca da responsabilidade internacional e seus desdobramentos quanto a atores não estatais a partir das categorias de Andrew Clapham, buscando construir ao final delas, o reconhecimento da subjetividade das denominadas empresas transnacionais. Antes porém, discorre como o processo da globalização e diminuição dos poderes estatais de regulamentação propiciaram o surgimento de novos e poderosos atores não estatais no cenário internacional, como as empresas transnacionais. Pretende ainda refletir como estas se tornaram titulares de obrigações perante o Direito Internacional dos Direitos Humanos, decorrendo daí o dever de reparação, o que fundamenta a necessidade de discutir sua responsabilização. Analisa ainda como os atuais espaços internacionais de queixas sobre violações de Direitos Humanos não são suficientes nem adequados quando da análise de casos que envolvam empresas transnacionais, visto que estes ainda reconhecem os Estados como os principais atores do sistema internacional, sugerindo assim a possibilidade de transformação dessa compreensão.

Palavras-chave: Globalização; Desrregulamentação; Atores não estatais; Empresas Transnacionais; Responsabilização Internacional.

\begin{abstract}
This study aims to examine the three main theories of international responsibility and its consequences as non-state actors from the categories of Andrew Clapham, seeking to build at the end of which the recognition of the subjectivity of so-called transnational companies. Before that, discusses how the process of globalization and reduction of state regulatory powers led to the emergence of new and powerful nonstate actors in the international arena, such as transnational companies. It also aims to reflect how these have become bondholders under international human rights law, follow from this duty to repair, which underlies the need to discuss accountability. It also analyzes how the current international spaces of complaints about human rights violations are not sufficient or appropriate in the analysis of cases involving transnational companies, since they still recognize the states as the principal actors in the international system, thus suggesting the possibility of transformation this understanding.
\end{abstract}

Key-words: Globalization; Desrregulamentação; non-state actors; Transnational Corporations; International accountability.

\footnotetext{
${ }^{1}$ Mestranda em Direitos Humanos pela Universidade Federal do Pará - UFPA, Pará (Brasil).

E-mail: marianaa.lucena@gmail.com

${ }^{2}$ Doutora em Direito pela Universidade Federal do Pará - UFPA, Pará (Brasil). Professora do Programa de PósGraduação em Direito pela Universidade Federal do Pará - UFPA, Pará (Brasil). E-mail: cfterezo@ hotmail.com
} 


\section{INTRODUÇÃO}

O poderio cada vez crescente das denominadas empresas transnacionais conduz ao necessário enfrentamento e reflexos da matéria empresas e Direitos Humanos, cuja questão principal reside na (im)possibilidade de responsabilização internacional destas, ante as limitações jurídicas que existem nas organizações internacionais responsáveis pela proteção dos Direitos Humanos, internacionalmente.

Fenômenos como a globalização e a gradual perda da capacidade estatal de regulamentação foram pano de fundo para a capacidade de que atores não estatais tenham se tornado titulares de direitos e obrigações, e assim, a partir de construções teóricas, políticas e jurídicas, sujeitos de Direito Internacional.

Desta feita, o presente artigo pretende analisar o contexto e fenômenos ligados ao arranjo atual das empresas transnacionais no cenário internacional, especialmente àquele atinente aos Direitos Humanos, apontando os avanços em termos de compreensões teóricas, que permitem a caracterização destes atores como sujeitos do Direito Internacional dos Direitos Humanos.

\section{GLOBALIZAÇÃO, DESRREGULAMENTAÇÃO TRANSNACIONAIS}

$\mathrm{Na}$ nova ordem globalizada, o empoderamento de organizações empresariais transnacionais $^{3}$ com a conseqüente ampliação e influência das instituições privadas ao redor do

\footnotetext{
${ }^{3}$ Faz-se necessário esclarecer que no presente artigo as violações de Direitos Humanos estudadas dirão respeito àquelas praticadas pelas denominadas empresas transnacionais, conforme conceito adotado pela Conferência das Nações Unidas para o Desenvolvimento (United Nations Conference on Trade and Development (UNCTAD)), a seguir transcrito: "A TNC is an enterprise, which is irrespective of its country of origin and its ownership, including private, public or mixed, which comprises entities located in two or more countries which are linked, by ownership or otherwise, such that one or more of them may be able to exercise significant influence over the activities of others and, in particular, to share knowledge, resources and responsibilities with the others. TNCs operate under a system of decision making which permits coherent policies and a common strategy through one or more decision-making centres. This definition does not regard the legal form and fields of activity of these entities.In the above definition, the term "entities" refers to both parent enterprises, defined below, and other enterprises.For working purposes, the UNCTAD considers a "transnational corporation" to be an entity controlling assets abroad. (Destaque não original)". Acesso em junho/2016. Disponível em http://unctad.org/en/Pages/DIAE/Investment\%20and\%20Enterprise/Structure-of-TNCs.aspx. Ainda sobre tal conceituação, Andrew Clapham em sua obra Human Rights Obligations of Non- State Actores, no capítulo 6, item 2, também conceitua empresas transnacionais. Para ele, a expressão "empresas transnacionais" diz respeito geralmente a uma única corporação jurídica que opera em mais de um país, com uma sede e um estatuto jurídico incorporado na legislação nacional do Estado de origem. Enfatiza que a transnacionalidade é essencial para compreender o fenômeno da responsabilização internacional desses atores não-estatais, considerando que a sede empresarial pode estar em um
} 
globo apresentam impactos positivos e negativos aos indivíduos e seus agrupamentos. No que diz respeito os impactos negativos cujo enfoque é o que importa no presente artigo, dado o objetivo de uma construção teórica que permita a responsabilização internacional de empresas transnacionais, tem-se que as afetações sofridas pelas vítimas e suas comunidades não têm sido eficazmente remediadas na maior parte dos Estados ante as relações existentes entre muitas empresas e as esferas de governo nacionais, nem em âmbito internacional, ante a ausência de norma vinculativa às empresas e os inócuos mecanismos de proteção existentes.

As últimas décadas do século XX têm trazido importantes transformações no cenário internacional e à forma em que se configuram as relações internacionais. Esses processos de mudanças têm sido descritos no marco do fenômeno socioeconômico conhecido como globalização (ORTEGA, 2008. p. 23). Uma das características que define este período histórico é a proliferação de atores não estatais, onde na comunidade globalizada interagem continuamente

Estado, seu sistema legal, os acionistas, as operações, os trabalhadores e os diretamente afetados por suas atividades, em outros Estados, distintos entre si. Sobreisso:

"6.2 TRANSNATIONALS, MULTINATIONALS, AND NATIONAL CORPORATIONS Much of thecommentaryonthetopicofcorporationsandhumanrightsconfusinglyconcentratesontheconceptofthetransnationalcorp oration. This is due in part to the history of the topic at the United Nations in the 1980s and the concern with protection for and against foreign corporations operating in the developing world. 18The term 'transnational corporation' emphasizes the fact that there is usually a single legal corporation operating in more than one country, with a headquarters and a legal statusincorporated in the national law of the home state. According to Rigaux: 'The concept of transnationality comes into its own when it is applied to an autonomous corporate system and, in this sense, the transnational corporation is one single corporation even if it is composed of corporations with separate identities under the corporation law of the States in which they operate.' 19 Legal systems do actually determine the 'nationality' of companies for various purposes. These rules are evolving as companies take on more and more elements of transnationality: the headquarters may be in one state, the legal incorporation in another state, the shareholders mostly from a third state, and the operations in a fourth state. If the workers are from a fifth state and those affected by the operations from yet another set of states, it becomes clear that highlighting transnationality is, in a way, essential to capture the phenomenon under discussion. The international texts use the terms 'transnational corporation', 'multinational enterprise', and 'business enterprise' in various contexts, 20 and this Chapter will use all of these terms as I discuss the various sets of standards. As legal systems become more comfortable with 'piercing the corporate veil', to reveal the true nature of the control by the parent over its offspring, 21 it may be that multinationality also usefully expresses the characteristics of these non-state actors for the purposes of legal accountability. The nationality of incorporation may no longer be the sole determinant for deciding issues of jurisdiction. In this sense, the corporation may be both operating transnationally and the bearer of multinationality. 22 So the adjective 'transnational' or 'multinational' can be employed to emphasize different characteristics of certain corporations. It does not really change the nature of the corporation as a legal entity. One might ask why purely national corporations seem to be excluded from the titles of the regimes seeking to ensure compliance with international standards by multinational corporations (MNCs), transnational corporations (TNCs), and multinational enterprises (MNEs). It is suggested here that, while larger companies may have greater responsibilities with regard to human rights obligations, 23 there is no reason to exclude purely national companies from the realm of such obligations. Although some texts, such as the OECD Guidelines, are specifically addressed to 'multinational' enterprises, the Guidelines stress that the same expectations are relevant to both multinational and domestic enterprises. CLAPHAM, Andrew. Human Rights Obligations of Non-State Actors (Collected Courses of the Academy of European Law) (Kindle Locations 48584862). OUP Oxford. Kindle Edition. 
Estados, organizações internacionais, instituições financeiras internacionais, grupos armados e organizações criminais, organizações não governamentais e empresas transnacionais, e apesar disto, o fazem no marco de um ordenamento jurídico essencialmente definido por e para os Estados.

Conforme SLAUGHTER (1997, p. 189), o acelerado processo de globalização enfraqueceu os Estados no que diz respeito à crescente perda de seus poderes de regulamentação. Tal fenômeno evidenciou lacunas em termos de responsabilidade dos Estados ligadas a formas de garantia, proteção e respeito dos Direitos Humanos, onde o fracasso da tutela estatal pode ser explicado pelo aumento da influência dos agentes privados sobre as políticas nacionais e internacionais em matéria de economia, comércio, legislação, questões trabalhistas, saúde, educação, desenvolvimento e outros aspectos importantes da vida em coletividade, tornando possível então observar que os Estados sozinhos não são capazes de garantir uma ampla proteção dos Direitos Humanos. Mais que isso, constatou-se que os Direitos Humanos estão propensos a violações por atores não estatais, como as empresas transnacionais.

Essas revelações aumentaram o desafio concernente à superação da compreensão convencional de que a responsabilidade internacional em matéria de Direitos Humanos se dá apenas a atores estatais. Assim, esse artigo pretende enfrentar a busca por parâmetros de responsabilização destes novos atores nos sistemas internacionais, que indicam que atores privados também devem respeitar e garantir os Direitos Humanos, além de repararem, em casos de danos, buscando apontar as conquistas no assunto, desafios e caminhos possíveis para a possibilidade de responsabilização de empresas transnacionais em nível internacional em casos de violações de Direitos Humanos.

A questão da responsabilidade empresarial das transnacionais, no Direito Internacional dos Direitos Humanos (DIDH) é uma das mais relevantes e atualmente debatidas no discurso contemporâneo dos Direitos Humanos. Em uma época de globalização, as políticas liberais de mercado, a privatização de empresas estatais especialmente em países em desenvolvimento, a promoção e incentivo de investimentos diretos vindos do exterior e a tendência à não regulamentação do setor privado têm especial pertinência quando da análise dos conflitos sociais observados na temática empresas e Direitos Humanos.

Para SLAUGHTER (1997. p. 192), a globalização assume importante destaque pois implica verdadeira erosão das fronteiras nacionais, afetando sensivelmente a capacidade de 
regulação dos Estados, visto que por exemplo, as empresas transnacionais podem facilmente “fugirem” de suas jurisdições. Além disso, a cessão de poder e competências para atores privados pelos Estados tratou de evidenciar que as ações estatais não são por si só, suficientes para garantir o gozo dos Direitos Humanos ${ }^{4}$.

No entanto, segundo CLAPHAM (Localizações Kindle 1264-1269), não é somente o desenvolvimento desse fenômeno e suas consequências no poder de regulamentação dos Estados que ameaçam os Direitos Humanos, mas sim as maneiras que estes fazem frente a este desenvolvimento, configurando em certos contextos um maior enfoque em seu papel internacional ${ }^{5}$.Segue afirmando que a globalização pode estimular novos modos de responsabilização de atores não-estatais, no que seria uma nova política global, cujo cenário é o Direito Internacional, porém adianta que muitos não partilham deste posicionamento.

Sobre a difícil, porém necessária interação entre a globalização e os Direitos Humanos, CLHAPHAM comenta o entendimento de ALSTON (Localizações Kindle 1258-1264) ${ }^{6}$ a respeito, onde enquanto a globalização tem como premissas a flexibilidade, adaptação, informalidade e celeridade, abarcando adjetivos de incontrolável, sem princípios e até mesmo antidemocrática, no sentido que muitos dos seus alvos não têm escolha a não ser se conformarem com seus objetivos, o regime dos Direitos Humanos é completamente distinto, podendo ser caracterizado como sólido, baseado em princípios, não facilmente manipulado, podendo ainda ser considerado como excessivamente gradualista, cauteloso, rígido e legalista. Conclui portanto que globalização e Direitos Humanos reúnem em si uma gama de características que os dissociam, e em seguida aponta como saída, conforme SLAUGTHER (Localizações Kindle 1252-1258), as tomadas de

\footnotetext{
${ }^{4}$ Especial enfoque pode ser dado aos DESCs, visto que com o aumento das privatizações, o acesso a serviços básicos como medicamentos essenciais, por exemplo, passam a depender das decisões e medidas políticas de grandes grupos farmacêuticos. $\mathrm{O}$ direito à habitação passa pelo crivo de bancos. $\mathrm{O}$ acesso à água, saneamento e eletricidade também se tornam dependentes de políticas de prestadores de serviços privados.Ainda em relação aos DESCs, o cumprimento das obrigações indiretas (âmbito interno) em nível internacional por via judicial tem sido em grande parte limitada pela dificuldade de reconhecimento da justiciabilidade dos mesmos. Porém, insta ressaltar o denominado litígio estratégico no processo judicial internacional em matéria de Direitos Humanos, utilizando os recursos judiciais possíveis, no terreno dos direitos civis e políticos, também encontra grande pertinência quando da análise dos direitos violados por atividades empresariais. Ver LANGFORD, Malcolm. Judicialização dos direitos econômicos, sociais e culturais no âmbito nacional: uma análise socio-jurídica. SUR. Revista Internacional de Direitos Humanos, n. 11, dez. 2009, p. 99-133. Disponível em: www.scielo.br/sur.

${ }^{5} \mathrm{O}$ grande papel dos Estados frente às afetações nos Direitos Humanos pelas empresas transnacionais no âmbito do DIDH encontra fundamento neste pensamento.

${ }^{6}$ Ibidem. Localizações Kindle 1258-1264.
} 
decisões transgovernamentais, onde existem vários estratos e instâncias, públicos e privadas, nacionais e internacionais.

\section{CONSIDERAÇÕES ACERCA DA RESPONSABILIDADE INTERNACIONAL EM CASOS DE VIOLAÇÕES DE DIREITOS HUMANOS}

Nesse contexto, o Direito Internacional enfrenta um importante desafio: dar resposta jurídica aos desafios impostos pelas dinâmicas da globalização. Um deles é o estabelecimento de parâmetros jurídicos da participação de atores não-estatais no ambiente internacional ${ }^{7}$. O presente artigo então trata de abordar parte das atuais discussões através da compreensão do papel das empresas transnacionais e a evolução de sua responsabilização internacional nos sistemas de proteção dos Direitos Humanos, visando possibilidade de total sujeição destas ao Direito Internacional dos Direitos Humanos em casos de violações.

Uma das principais consequências da globalização tem sido a consolidação de um modelo multifacetado de mercado e a exaltação da inversão estrangeira direta como elemento fundamental do processo de desenvolvimento econômico dos Estados e sua população.

As empresas transnacionais como principais canalizadoras de investimentos e agentes centrais no comércio internacional estão adquirindo cada vez mais relevância na sociedade internacional contemporânea. Porém, sobretudo, têm aumentado sua capacidade para afetar as condições de vida dos indivíduos e têm uma participação determinante no gozo dos Direitos Humanos $^{8}$. A discrepância entre o poder das empresas transnacionais a resposta do Direito Internacional desemboca em uma lacuna na proteção dos Direitos Humanos que é necessária cobrir.

\footnotetext{
${ }^{7}$ Leia-se: sua responsabilização.

${ }^{8}$ Como exemplo, é possível citar os nocivos impactos ambientais decorrentes das atividades empresariais. A esse respeito, Pérez Luño aduz: “[...] Al próprio tempo, em el curso de estos últimos anos, pocascuestioneshan suscitado tan amplia y heterogéna inquietude como la que se refiere a las relaciones delhombre com su médio ambiental em el que se hallainmerso, que condiciona su existência y por el que, incluso, puedellegar a ser destruído. La plurissecular ensión entre naturaliza y sociedad corre hoyelriesgo de resolverseen términos de aberta contradiccióncuandolasnuevas tecnologias concibenel domínio y laexplotaciónsin limites de la naturaliza como la empresa más significativa del desarrolho. Los resultados de al planteamientoconstituyenahoraladegradación y contaminacióndel médio ambiente, hantenidosu pontual repercusiónenel hábitat humano y enel próprio equilíbrio. PEREZ LUÑO, Antonio-Enrique. Concepto y concepción de losderechos humanos : (acotaciones a laponencia de Francisco Laporta). Doxa. N. 04 (1987). ISSN 0214-8876, p. 57. Disponível em http://www.cervantesvirtual.com/obra/concepto-y-concepcin-de-losderechos-humanos-acotaciones-a-la-ponencia-de-francisco-laporta-0/0050e216-82b2-11df-acc7-002185ce6064.pdf. Acesso em junho/2016.
} 
A intenção de controle da conduta das empresas transnacionais no nível internacional não é desconhecido. No marco das iniciativas para o estabelecimento de uma nova ordem econômica internacional a formulação de princípios para o dito controle se propõe como um dos objetivos de uma comunidade internacional mais equilibrada e justa e que não alcançou consenso sobre o tema da responsabilização dos atores não-estatais ${ }^{9}$.

Dito isto, pode-se afirmar que a possibilidade de reparações a vítimas de violações de Direitos Humanos se dá a partir dos horrores da Segunda Guerra Mundial, com o crescimento e fortalecimento dos sistemas de proteção e promoção de Direitos Humanos, como o Sistema Global e os Sistemas Regionais, quais sejam, o Sistema ONU, e os Sistemas Interamericano, Europeu e Africano $^{10}$.

Visto que o instituto da reparação liga-se estreitamente à responsabilidade internacional, DÍAS CÁCEDA (2008. p. 49) esclarece que esta última corresponde precipuamente à obrigação de proteção dos Estados às pessoas que estão sob sua jurisdição.

Para SANTIAGO NINO (2003. p. 142), o Direito Internacional é fundado nas normas consetuedinárias, que são aquelas que se originam das reiteradas atitudes dos Estados, sendo incomuns normas atuais que têm origem em organizações internacionais, sejam elas global ou regionais, dado seu caráter muitas vezes não vinculante. Desta feita, derivada do Direito Internacional clássico, a responsabilidade internacional tem fundamento no direito consetuedinário ${ }^{11}$ e pautada nos Estados enquanto únicos sujeitos de Direito Internacional.

\footnotetext{
${ }^{9}$ Sobre o consenso internacional na questão empresas e Direitos Humanos, Jhon Ruggie afirma: “[...] eu queria evitar a todo custo que meu mandato fosse aprisionado por longas negociações entre governos por causa de um texto jurídico que eu achava ser inconclusivo, na melhor das hipóteses, e possivelmente até mesmo contraproducente. Era muito importante que os parâmetros e perímetros da questão das empresas e direitos humanos ficassem protegidos em termos de políticas legítimas, que pudessem ser executadas imediatamente e sobre as quais poderiam se desenvolver. Portanto, fui muito cuidadoso ao basear os elementos obrigatórios dos Princípios Orientadores nas implicações de normas legais já existentes para Estados e empresas; e também para complementar essas normas com os fundamentos de políticas dirigidas aos interesses e valores dos dois grupos em questão; e, além do endosso do Conselho de Direitos Humanos, também trabalhei para que elementos essenciais dos Princípios Orientadores fossem adotados como exigências das políticas de outros órgãos com autoridade e responsabilidade para fazer isso. Resumindo, meu objetivo era conseguir uma fórmula politicamente legítima, e não um instrumento com obrigatoriedade jurídica. RUGGIE, John (2014-0320). Quando Negócios Não São Apenas Negócios: As Corporações Multinacionais e os Direitos Humanos (KindleLocations544-550). Editora Planeta Sustentável. KindleEdition.

${ }^{10}$ DÍAZ CÁCEDA, Joel. La responsabilidad internacional de los Estados: base para la defensa de losDerechos Humanos. Derecho PUC, Peru, n. 61, 2008, p. 249.

11 Sobre o direito consetuedinário, ver ZÚÑIGA CARDOZA, Rubén. A dicotomia jurisdicional entre direito interno e direito internacional em matéria de Direitos Humanos. Meritum, Belo Horizonte, v. 5, n. 2, 2010 , p. 136.
}

Revista de Direitos Humanos em Perspectiva | e-ISSN: 2526-0197 | Curitiba | v. 2 | n. 2 | p. 162-174 | Jul/Dez. 2016. 
Ocorre que segundo KNOX (2008. p. 19), a atual concepção do Direito Internacional concebe a ideia de que atores privados têm direitos e também deveres, tais como o de não cometerem guerras, crimes contra a humanidade ou genocídio. Segue afirmando ser possível a aplicação pelo Direito Internacional, de obrigações horizontais de não violação dos direitos humanos a esses atores.

Para ele, por muitos anos o DIDH ter imposto obrigações estatais de garantia, respeito e reparação em relação aos Direitos Humanos e poucas a atores não-estatais, configurando um alinhamento vertical, e não horizontal. Porém, essa visão tem sido regularmente contestada, especialmente considerando a dupla perspectiva benéfica da horizontalidade dos Direitos Humanos. A primeira delas reside no fato que os recursos internos dos Estados são muito maiores que a das organizações internacionais quanto à possibilidade de assegurar a proteção, respeito e reparação de direitos. Em segundo, com uma nova compreensão de sujeição de atores não-estatais, surgiria o papel crucial do DIDH de impor obrigações a estes, em certos e especiais casos de violações.

Para CARVALHO RAMOS (2014. p. 258), existem duas modalidades de eficácia horizontal de normas de tratados internacionais de Direitos Humanos. A primeira delas reside no reconhecimento, no corpo do próprio documento, a vinculação dos particulares aos direitos ali protegidos, incluídas as obrigações ${ }^{12}$. A segunda liga-se à obrigação estatal de garantia dos Direitos Humanos, onde este deve impedir que particulares o vulnerem.

Nesse sentido, a violação massiva dos Direitos Humanos por negligência ou falência dos Estados torna urgente o enfrentamento das violações causadas em contextos de atividades lucrativas, especialmente ao se considerar que os Direitos Humanos e os princípios gerais do Direito Internacional, incluídos aí os principais aspectos da responsabilidade internacional, devem ser considerados como fazendo parte de um mesmo todo, posto que são complementares e se reforçam mutuamente.

A globalização e o consequente novo contexto internacional demanda uma atenção ao problema da regulação das empresas transnacionais a partir do discurso dos Direitos Humanos.

\footnotetext{
${ }^{12}$ Importante relembrar o início desta pesquisa, ao tratar a Convenção para a Eliminação de Todas as Formas de Discriminação Racial, a Convenção para a Eliminação de Todas as formas de Discriminação contra a Mulher e outras, que enfrentam o dever estatal de combater a discriminação cometida por indivíduos e/ou empresas.
} 
A inclusão das empresas transnacionais entre os objetos de regulação do Direito Internacional, e a consideração pelo mesmo dos atores não-estatais em geral, é tema que tem atraído grande atenção no meio jurídico e acadêmico nos últimos anos. Tais contribuições parecem indicar que é necessário indagar ainda mais a teoria e a prática jurídicas internacionais com o intuito de clarificar não só o status jurídico internacional desses atores, mas o alcance de seus direitos e obrigações, bem como mecanismos eficazes de implementá-los.

Assim, uma vez considerada a obrigação de que as empresas cumpram os Direitos Humanos e inclusive os reparem, porém internamente, passa-se à investigação acerca das teorias existentes que sejam capazes de fundamentar a alteração da compreensão atual de que empresas transnacionais não são sujeitos do DIDH, pretendendo reunir argumentos que levem à construção futura da possibilidade de responsabilização internacional destes atores.

\section{FUNDAMENTOS TEÓRICOS PARA A CARATERIZAÇÃO DA RESPONSABILIDADE INTERNACIONAL DAS EMPRESAS TRANSNACIONAIS: UMA CONTRUÇÃO POSSÍVEL?}

$\mathrm{Na}$ atualidade, inúmeros exemplos são capazes de demonstrar que atores privados podem violar os Direitos Humanos, e assim indicam o próximo ponto crucial neste artigo: a necessidade de que as empresas transnacionais sejam consideradas sujeitos do DIDH.

A partir deste cenário, o debate acerca da aplicabilidade dos Direitos Humanos para agentes privados segue duas linhas principais, claramente definidas e distintas, quais sejam, a de que tais agentes possam e devam ser responsabilizados por violações de Direitos Humanos, tanto a nível nacional, mas especialmente, internacional, onde se pugna a criação de um instrumento vinculante, e outra, com apoio da poderosíssima comunidade empresarial e Estados mais ricos ao redor do globo, que sustentam que a proteção dos Direitos Humanos no espaço internacional, continua exclusiva aos Estados, muito embora as empresas possam auxiliar em sua promoção, proteção, respeito e reparação.

As empresas transnacionais tem se visto envolvidas em violações aos Direitos Humanos em dimensões muito maiores às que quaisquer particulares podem cometer, de modo que aspectos de ordem jurídica, política e sociológica permitem evidenciar que na atualidade um dos problemas relacionados com a responsabilidade das empresas em casos de violações de Direitos Humanos é 
que não existe uma estrutura jurídica que permita imputar responsabilidade internacional às empresas transnacionais por violações aos Direitos Humanos ${ }^{13}$.

Por essa razão são buscados elementos teóricos suficientes para caracterizar a responsabilidade internacional das empresas transnacionais, ante a existência de certos elementos jurídicos que permitem imputar a responsabilidade internacional às empresas transnacionais por violações de Direitos Humanos, a seguir expostos.

As três principais aproximações teóricas partem de Clapham, em três categorias definidas pelo autor. A primeira delas reconhece aos Estados e apenas a estes a única titularidade das obrigações derivadas do DIDH (Localizações Kindle 1298-1302). Tal posição dá ênfase à responsabilidade estatal e estabelece que em casos que particulares cometam atos que vulnerem os Direitos Humanos, estes deverão ser observados à luz da obrigação que têm os Estados de garantir o respeito aos Direitos Humanos.

Tal consideração abriga a ideia de que alargar as obrigações a atores não estatais outorgaria uma legitimidade que afetaria ou minaria a autoridade do Estado e diluiria suas responsabilidades, com respeito às suas obrigações em matéria de Direitos Humanos.

De acordo com o autor, a segunda aproximação se liga ao tema da eficácia dos direitos humanos entre particulares, se sustenta na ideia de que é necessário encontrar novos caminhos para fazer frente à globalização (Localizações Kindle 1293-1298). Nesse sentido, se sugere que os Estados são cada vez menos relevantes e perdem mais o seu poder, de modo que a atenção deve também se mirar em outros atore, como as empresas transnacionais, de modo que em uma economia globalizada, o mercado que acompanha a exploração econômica e seus desdobramentos e conflitos sociais já não se encontra apenas abaixo do domínio estatal.

Retomando as ideias anteriores sobre a desregulamentação estatal já trazidas neste artigo, conclui-se que à medida que os Estados perdem seu poder de regulamentação, aparecem novos atores, estes não estatais, de modo que o sistema estatal é reorganizado a partir de um arranjo distinto, com a interação de distintos atores, de modo que esses novos atores terão capacidade para estabelecer e estarem sujeitos a novas normas.

\footnotetext{
${ }^{13}$ Nesse sentido, atualmente inexiste uma estrutura jurídica que permita imputar responsabilidade internacional às empresas transnacionais por violações de Direitos Humanos, no sentido de que não existe uma normatividade e estrutura internacionais que protejam os Direitos Humanos quando estes são vulnerados por estes atores.
} 
A terceira e última categoria buscar ir para além da visão tradicional acerca da responsabilidade internacional pautada apenas no Estado, com o argumento de que os espaços normativos não são oriundos diretamente de órgãos estatais, mas de outras instâncias que também são obrigatórias para os indivíduos sujeitos a elas.

Dito isto, Clapham admite que o DIDH permite afirmar que os Estados não são os únicos sujeitos de direito internacional, visto que atores não estatais como as empresas transnacionais gozam de privilégios e direitos que antes eram somente estatais. Ele conclui que os direitos e deveres internacionais dependem da capacidade do sujeito para ser titular de tais, e não da subjetividade dos atores.

Assim, para ele, existem normas que ordinariamente foram criadas por e para os Estados, mas que atualmente também se aplicam a atores não estatais, de modo que estes podem ser considerados sim responsáveis pela violação de tais normas, o que exige uma radical postura dos sistemas regionais e global de proteção dos Direitos Humanos, por meio de seus órgãos, bem como a criação de instrumentos vinculantes que finalmente permitam e concretizem a responsabilização em âmbito internacional de empresas transnacionais por violações de Direitos Humanos.

\section{CONSIDERAÇÕES FINAIS}

No presente trabalho foram analisadas três das principais posições ou teorias a respeito da responsabilidade das empresas transnacionais em casos de violações de Direitos Humanos, a partir de Andrew Clapham, indicando que os sistemas internacionais de proteção dos direitos humanos podem permitir que as empresas transnacionais sejam submetidas ao Direito Internacional dos Direitos Humanos, e assim fazer com que sejam responsáveis em casos de violações de Direitos Humanos.

Tal reflexão se faz necessária visto que, desde o ponto de vista dos sistemas de proteção de Direitos Humanos existentes, estes não são suficientes nem eficazes na proteção de direitos, em casos de violações cometidas por empresas transnacionais.

A responsabilidade internacional das empresas se mostra então como consequencia de um dano que se causa em razão de uma ação ou omissão de dada empresa transnacional, no não cumprimento de uma ou mais normas vigentes em matéria de Direitos Humanos, e que dá lugar a uma reparação. 


\section{REFERÊNCIAS}

CLAPHAM, Andrew. Obrigações de direitos humanos de atores não-estatais (Cursos recolhidos da Academia de Direito Europeu) (Localizações Kindle 1298-1302). OUP Oxford. Edição Kindle.

BURGORGUE-LARSEN, Laurence. El contexto, las técnicas y las consecuencias de la interpretación de la Convención Americana de los Derechos Humanos.EstudiosConstitucionales, a. 12, n. 1, 2014.p. 105-161.

CANÇADO TRINDADE, Antônio Augusto. Direito das Organizações Internacionais. Belo Horizonte: Del Rey, 2014. Introdução à primeira edição. p. 1.

CARVALHO RAMOS, André de. Teoria geral dos direitos humanos na ordem internacional. São Paulo: Saraiva, 2014. p. 125.

CLAPHAM, Andrew. Human Rights Obligations of Non-State Actors (Collected Courses of the Academy of European Law.OUP Oxford. Kindle Edition.

DÍAZ CÁCEDA, Joel. La responsabilidad internacional de los Estados: base para la defensa de losDerechos Humanos. Derecho PUC, Peru, n. 61, 2008, p. 219-271.

FEENEY, Patricia. A luta por responsabilidade das empresas no âmbito das Nações Unidas e o futuro da agenda de advocacy. Disponível em http://www.scielo.br/scielo.php?script=sci_arttext\&pid=S1806-64452009000200009. Acessado em nov./2015.

HOMA - Centro de Direitos Humanos e Empresas. Campus da Universidade Federal de Juiz de Fora. Faculdade de Direito. Disponívelemhttp://homacdhe.com/index.php/pt/

JACKSON, Vicki C. Constitutionalengagement in a transnational era. Oxford: Oxford UniversityPress, 2010.

KNOX, J.H. 2008.Horizontal human rights law. American Journal of International Law, v. 102, p. 1-47.

MATHIS, Adriana de Azevedo. Responsabilidade Social Corporativa e Direitos Humanos. Revista Katáysis. v. 1. 2012. p.131 - 140.Disponível em https://periodicos.ufsc.br/index.php/katalysis/article/view/S1414-49802012000100014. Acessado em novembro de 2015.

NAÇÕES UNIDAS. 1948. Declaração Universal dos Direitos Humanos. Disponível em http://www.ohchr.org/EN/UDHR/Documents/UDHR_Translations/por.pdf. Acessado em jan./2016. Acesso em junho/2016. 
SANTIAGO NINO, Carlos. Introducciónalanálisisdelderecho. Editorial Astrea. Buenos Aires, 2003. $\quad$ p. $142 . \quad$ Disponível em https://inecipcba.files.wordpress.com/2013/08/introduccion_al_analisis_del_derecho__carlos_santiago_nino.pdf. Acessado em junho/2016.

ORTEGA, Olga Martín. Empresas Multinacionales y Derechos Humanos enDerecho Internacional, Bosch, Barcelona, 2008, p. 23. Disponível em https://www.google.com.br/url?sa=t\&rct=j\&q=\&esrc=s\&source=web\&cd=5\&cad=rja\&uact=8\& ved=0ahUKEwjytMnyy9XOAhVEjJAKHV8qDLkQFgg4MAQ\&url=http\%3A\%2F\%2Fearchivo.uc3m.es\%2Fbitstream\%2Fhandle\%2F10016\%2F19041\%2FTFM_MEADH_Carlos_Asu nsolo_2014.pdf\%3Fsequence\%3D1\&usg=AFQjCNEKwkuUAtFS7Z3euE3mJdYqJgwP0w\&sig 2=q4NVJUaYIrMS37K17rkxWA. Acessoemjunho/2016.

PIOVESAN, Flávia. Direitos Humanos e o direito constitucional internacional. $12^{\mathrm{a}}$ ed. rev. e atual. São Paulo: Saraiva, 2015.

RAMOS, André de Carvalho. Processo Internacional de Direitos Humanos. $2^{\text {a }}$ ed. São Paulo: Saraiva, 2012.

RUGGIE, John (2014-03-20). Quando Negócios Não São Apenas Negócios: As Corporações Multinacionais e os Direitos Humanos. Editora Planeta Sustentável. KindleEdition.

SALMÓN, Elizabeth. Curso de derecho internacional público. Lima: Fondo Editorial de la Pontificia Universidad Católica del Perú, 2016. 2. Ed.

SLAUGHTER, Anne-Marie.The real new world order.ForeignAffairs 76. n. 5. 1997. p. 183197. Disponível em www.foreignaffairs.com/articles/1997-09-01/real-nwe-world-order. Acesso em junho/2016.

TEREZO, Cristina Figueiredo. Sistema Interamericano de Direitos Humanos: pela defesa dos direitos econômicos, sociais e culturais.Curitiba: Appris, 2014.

TRATADO INTERNACIONAL DOS POVOS PARA O CONTROLE DAS EMPRESAS TRANSNACIONAIS, elaborado pelo Observatório de Multinacionais na América Latina. Disponível em http://omal.info/spip.php?article6438. Acessado em abril/2016.

ZÚÑIGA CARDOZA, Rubén. A dicotomia jurisdicional entre direito interno e direito internacional em matéria de Direitos Humanos.Meritum,Belo Horizonte, v. 5, n. 2, 2010, p. 125159. 